

\begin{abstract}
In this paper, I explore the emergence of happiness and well-being as keystones of contemporary EuroAmerican culture. Drawing on the relationship between disciplinary enterprises and forms of governance, as well as on cross-cultural comparison with fa'asamoa (the Samoan Way), I work to situate the current EuroAmerican obsession with happiness and well-being as a cultural formation that is, as an artifact of a historically and culturally unique set of patterns and forces - thus problematizing its taken-for-granted status, in academic and policy-making circles, as a self-evident and universal goal with universal characteristics. I pay particular attention to the forms of governance that the contemporary orientation to happiness inaugurates and instantiates.
\end{abstract}

Keywords: neoliberalism; cultural \& historical specificity 


\title{
Happiness:
}

\section{Notes on History, Culture and Governance}

\author{
C. Kingfisher
}

\section{Introduction}

In recent decades, an increasing interest in happiness and well-being has come to permeate popular, scholarly, and governmental imaginaries and practices, embodying a $20^{\text {th }}-21^{\text {st }}$ century iteration of a concern that has deep historical roots in a number of philosophical and religious traditions. Driven in part by the newly emergent sub-disciplines of positive psychology and happiness economics, and highlighted in local, national, and international fora, these new engagements with happiness signal a paradigm shift in orientations to governance - to work on society and work on the self.

Bhutan's 1973 development of a Gross National Happiness Indicator, meant to challenge the hegemony of Gross National Product as an appropriate measure of well-being and prosperity, marks the starting point of what I call the (contemporary) culture of happiness. Since that time, a popular obsession with happiness has taken hold in Canada, the U.S. and parts of Western Europe. This burgeoning culture has been materialized in a political economy of happiness, or "happiness industry" (Gunnell 2004), in which markets for anti-depressants, self-help books, psychotherapy, yoga, meditation, exercise and diet regimes, etc., are proliferating. Not only that, but happiness has taken on the shape of a cultural imperative, in which it has become a social obligation. Happiness, in other words, is something we actively monitor and cultivate, and, indeed, something we must have - a key, or, perhaps, the key item of desire in consumer society.

Happiness is not only a popular concern, however, but also an emerging academic enterprise. The last decade of the $20^{\text {th }}$ and first decade of the $21^{\text {st }}$ centuries witnessed the development of several academic subdisciplines focused on happiness, with the accompanying creation of new journals, ${ }^{1}$ the launching of academic institutes for the study of well-being, ${ }^{2}$ and innumerable conferences on the topic. A number of governing bodies have also taken up the mantel of well-being. France and Britain, for instance, have each taken steps to incorporate happiness measures and programs into their governing structures (Dolan, Peasgood and White 2006; Ferguson 2007; Stiglitz, Sen and Fitoussi 2009); Canada has developed its own Index of Wellbeing; and, in 2011, the UN General Assembly invited its member states to "pursue the elaboration of additional measures that better capture the

\footnotetext{
${ }^{1}$ For example, the Journal of Happiness Studies, and the Journal of Positive Psychology.

2 For example, the Well-Being Institute at Cambridge University, and the Positive Psychology Center at the University of Pennsylvania.
} 
importance of the pursuit of happiness and well-being in development with a view to guiding their public policies" (UN News Centre, 7/19/2011). The UN's launch of the International Day of Happiness (March 20) provides further indication of the spread of a culture of happiness beyond EuroAmerican ${ }^{3}$ contexts. Happiness, then, seems to have become a contemporary point of focus in peoples' everyday lives, a flourishing business, a subject of academic inquiry, and a policy concern.

A key feature of the culture of happiness - and the problematic that informs this discussion - is its takenfor-granted status. Few have queried why happiness has (re)emerged as a key concern at this particular historical juncture, or how it might be related to other cultural formations, and, specifically, to forms of governance. Indeed, there has been little recognition that current approaches represent a specifically EuroAmerican cultural formation. On the contrary, rather than situating our frameworks of well-being as culturally and historically specific, the selfhelp industry, pharmaceuticals, and even many academics and policy-makers treat them as transparently and universally self-evident. In the face of the emergence of entire industries, careers, and potentially even government bureaucracies oriented to well-being, then, few seem to be wondering what it is all about. The concern with happiness is, of course, nothing new, but what we've been witnessing in recent decades is a new iteration, a renewed emphasis that is taking particular shapes in specific cultural and political contexts. This renewal, and these particular shapes and contexts, are worth querying.

There have, of course, been some notable exceptions to the general pattern of taking for granted the turn to happiness, as historians and critical scholars have in the past decade begun to offer various readings of its emergence and character. McMahon (2006, 2010), for instance, situates happiness in historical context, tracing temporal shifts in conceptualization and orientation in what he refers to as "western" philosophical, religious, and political traditions. These shifts serve to highlight the historical uniqueness of our current constructions. To give another example, Ahmed (2010) draws on feminist and anti-racist theories to provide a nuanced analysis of the power relations involved in current efforts to promote happiness, thereby exposing the ugly underbelly of well-being: the obligations, the blaming, and the coercions. Others, such as Ferguson (2007), Ehrenreich (2009, 2010), and McDonald and O'Callaghan (2008), have similarly explored the connections between the concern with happiness and neoliberalism. Finally, some scholars have begun to criticize the ethnocentrism of purportedly universally valid cross-cultural measures of happiness by both situating disciplines such as positive psychology as cultural artifacts (Christopher and Hickinbottom 2008), and exploring non-EuroAmerican constructions of well-being (e.g., Johnston et al. 2012; Mathews and Izquierdo 2009).

In this paper, I join this small but growing group of critics in stepping outside of an unquestioning adoption of happiness as a self-evident and universal goal in order to explore the culture of happiness from an anthropological perspective. ${ }^{4}$ I link the three approaches I have described above - history, cross-cultural analysis, and an analysis of

${ }^{3}$ I use EuroAmerican as shorthand for Canada, the U.S., and parts of Western Europe, but also as much to refer to an orientation as a place.

${ }^{4}$ Historically, anthropology's engagement with the study of happiness and well-being has been latent rather than explicit (Johnston et al. 2012; Mathews and Izquierdo 2009; Thin 2009). Thus Thin (2009: 26; see also Thin 2005, 2012) bemoans a "well-being deficit in anthropology," which he attributes to, among other causes, the discipline's foci on relativism and on suffering. Mathews and Izquierdo (2009:9) further claim that, "well-being, as an analytic rather than ethnographic term, tends to be used much more by social scientists than by a given people themselves in describing their lives; but it is the latter that anthropologists have generally focused upon in their ethnographic portrayals." Finally, Johnson et al. (2012) underscore the complexities of cross-cultural 
power and governance, which are generally distinct in the literature (although see Christopher and Hickinbottom 2008) - with two goals in mind. The first is to challenge mainstream social science approaches to happiness, which, despite their origins in primarily EuroAmerican contexts, claim to provide universally applicable insights and policy frameworks. Based primarily on survey-based and other statistical data, the cross-national comparisons typical of happiness studies have generally not been informed by fine-grained, nuanced analyses of culturally specific models, practices, and experiences of happiness and well-being. This is unfortunate, as the latter can serve to both mitigate the dangers of ethnocentrism that often accompany the universal application of survey measures developed in particular cultural contexts, and provide the grounds for more appropriate and accurate forms of comparison. In addition, there is a tension running through happiness studies between individualist versus collectivist approaches to understanding and producing the good life that pivots around contestations over where to locate the etiology and maintenance of happiness and well-being - in individuals, in systems of government, or in particular relationships between the two - that are often undertheorized, or even unarticulated. As with mainstream cross-national analyses, narrowly EuroAmerican cultural frameworks provide the parameters of the individualist-collectivist debate.

My second goal is to sketch a theoretical and methodological framework that simultaneously allows for cross-cultural analyses that do not violate the integrity of non-EuroAmerican cultural formations, and maps an approach to the EuroAmerican culture of happiness as an artifact of specific rather than universal configurations of meaning and political economy.

My discussion is divided into three sections, throughout which I make connections between the academic disciplines of positive psychology and happiness economics, on the one hand, and disciplinary institutions and practices (in the broadest sense), on the other. I begin with a brief discussion of historical specificity in order to make the point that even within EuroAmerican cultures dominant approaches to happiness are of relatively recent vintage. What is taken for granted now, in other words, hasn't always been so - and in some ways is in marked contrast to dominant constructions of earlier periods. I then move from historical specificity to cultural specificity, using as my empirical referent fa'asamoa (the Samoan Way), a distinctively non-EuroAmerican approach to wellbeing. Finally, I return to the EuroAmerican context to make connections between the culture of happiness and neoliberal forms of governance. My goal here is to point to the power relations that run through what we typically take to be liberating and fulfilling. Throughout my discussion, I use the terms happiness and well-being to cover the range of "subjective" (internal feeling states) and "objective" (health statistics, literacy rates) interests that have been taken up by scholars in the social sciences. I use the terms loosely, without clear definitions, and interchangeably, to signal the recognized difficulties of pinning down precisely what is being referenced (e.g., Bok, D. 2010; Bok, S. 2010; Gilbert 2006; Kingwell 1998; Mathews and Izquierdo 2009; McMahon 2006, 2010; Schumaker 2007; Thin 2009; Weiner 2008) - difficulties that are exacerbated in the context of cross-cultural analysis.

comparison of phenomena as elusive and contextually specific as happiness and well-being. Recently, however, anthropology has both criticized the ethnocentrism of much cross-cultural happiness research, and launched its own efforts at comparative analyses that do not violate the integrity or reduce the complexity of cultural systems (Johnston et al. 2012; Mathews and Izquierdo 2009; Thin 2009). 


\section{History}

I take as my entry point positive psychology, which, in keeping with its parent discipline, is based on psychological models of the person that hold that "life can be conceived instrumentally as comprising a series of goals that one is in the process of trying to achieve. For psychology to be able to explain human behavior at all, behavior must be conceived as intentional, with actions determined by motives and goals" (Miller 2008:594). According to Miller (ibid.), positive psychology "simply takes this further and promises that all can achieve their goals, provided that attitudes are sufficiently positive."

While seemingly commonsensical - I would argue hegemonic - this psychological approach makes particular assumptions that are, in fact, historically unique rather than universal. Most importantly, it gives primacy of place to interiority, a form of ego-centrism that has not always been foregrounded in EuroAmerican contexts. Taylor (1989), for example, points to a shift with the rise of modernity from a two-tiered system, in which selves were firmly rooted within "a broad cosmological framework that imbued the world with meaning and value," to a one-tiered system, in which broader frameworks of meaning are "optional, arbitrary, or relativistic" (Christopher and Hickinbottom 2008:567). This does not, of course, mean that we do not inhabit a social universe; rather, it means that we live in a cultural context imbued with "choice" and arbitrariness, in which we supposedly make our own way and choose our own fate. In other words, it means that we are oriented primarily inwards rather than outwards, and that our interior life is constructed as relatively autonomous and only self-directedly attached to selected external constructions. Nor does it mean that work on the self - by which I mean various practices of self-discipline - are new; rather, it is the broader context of work on the self that seems to have been considerably narrowed, such that there is supposedly little need to refer to anything outside of ourselves.

Numerous critics have commented on this state of affairs. In their analysis of its construction of authentic happiness (the title of Seligman's 2002 book), for instance, Christopher and Hickinbottom (2008:576) lament the lack of an anchor in positive psychology's emphasis on the "meaningful" life, which, they claim, does not ground the components of authentic happiness "in any broad ethical theory or conception of the good life," but, rather, frames these components simply as "different orientations' to happiness that derive value through their ability to produce individual satisfaction [...] The source of personal meaning is irrelevant [...] All that matters is that you have some." Whether we find this situation lamentable or not is not my point. What is my point is that the selfreferentiality of a one-tiered system is unique in the context of a longue durée characterized by overarching cosmological and ethical frameworks within which meaning and practice were situated. I am less interested in seeing this as a good or bad thing than in seeing is as a phenomenon, an historical artifact worth noting so that we can attend to the characteristics of the air we breathe rather than take them for granted.

One key implication of one-tiered interiority is that it leads to a construction of happiness as having to do with emotional satisfaction and positive affect; in other words, as something marked by the presence of good feelings and the absence of bad feelings, or suffering (Christopher and Hickinbottom 2008). Like the focus on interiority, this construction is also historically unique. In his tome, Happiness: A History, for instance, McMahon (2006:7) argues that in early Greek philosophy happiness was "not a feeling, nor any subjective state." Rather, it was "a characterization of an entire life that can be reckoned only at death." In this framework, happiness was about a life well lived and lost, something that was determined objectively and externally, after the fact. Happiness was also for the most part restricted to the gods, and on those occasions when it did touch the realm of humanity, it had to do with the whim of the gods, with sheer dumb luck, with happ, or happenstance, as the etymology of the word implies, in lives assumed to be beset with difficultly and misery. Life was no so much made as endured, and happiness was certainly not something that was under human control or will. 
The story McMahon tells in tracing the philosophical and religious shifts from this early Greek framework to contemporary constructions is long and convoluted, ranging from approaches that focus on the cultivation of virtue and the renunciation - or fulfillment - of desire, to

suffering as a method of redemption; from other-worldly (or, after-death) to this-worldly orientations; from an emphasis on a golden past to one on a golden future; from the cultivation of joy to the romanticizing of melancholy; from the disciplining of interior habits to the construction of particular socio-political contexts; from happiness as evolutionarily maladaptive to happiness as evolutionarily adaptive; from happiness as something that is best left to the individual to happiness as something that is the appropriate purview of government policy. Despite these meanderings, however, two clear patterns emerge. First, approaches to happiness - including both what it is and how to produce it - have shifted radically over time. Such shifts signal that happiness is not transparently selfevident; it is not something that exists "out there" that we can perceive in unmediated form; rather, we construct it in different ways in different times. Thus there is little that we can take for granted; on the contrary, we should assume nothing. Second, these historical shifts seem to have followed a general trajectory in which happiness has moved from something that was the purview of the gods and that required divine intervention in order for humans to experience it, to something that humans could achieve on their own, to something that all humans had the right to, and finally, to something that all humans are personally responsible for and even obliged to achieve (Mahon 2006, 2010). Indeed, McMahon, along with others (e.g., Kingwell 1998), argues that our current understandings of and approaches to happiness emerge only in the relatively recent context of the Enlightenment. Happiness as a subjective state, and as something subject to human agency, are thus ideas that emerged at particular historical junctures, rather than foundational, universal, natural and self-evident truths.

\section{Culture}

Exploring temporal emergences and transformations is one method for denaturalizing the taken-forgranted. A second is cross-cultural comparison - tracking a phenomenon across space rather than time in order to place into relief the local specificity of what is often asserted as cross-culturally universal. To illustrate the importance of cross-cultural analysis to contemporary academic and policy approaches to happiness, I take as my reference point fa'asamoa (the Samoan Way), which situates happiness in the social rather than the individual. I begin, however, with a further exegesis of positive psychology, along with happiness economics, in order to underscore the cultural specificity of their analytic frames.

Launched in the late 1990s, positive psychology is built on the claim that psychology as discipline has suffered from an over-emphasis on what is wrong (mental illness, distress, crisis), rather than on what is right (strengths, capacities, positive emotions) (Csikszentmihalyi 1990, 1997; Linley et al. 2006; Gable and Haidt 2005; Seligman 2002, 2006; Seligman and Csikszentmihalyi 2000). At the foundation of positive psychology, then, is the idea that we should focus on enhancing the positive instead of fighting the negative. The key method for doing this is work on the self via therapy, meditation, and various disciplines of positive thinking, all with the goal of producing a positive attitude, which is itself a form of happiness. Although its orientation seems to be overwhelmingly on the isolated individual abstracted from any kind of social context, ${ }^{5}$ positive psychology does nod

${ }^{5}$ See Douglas and Ney (1998) for discussion of the abstract individual in social science in general, and in policy contexts in particular. 
to the social, and its proponents accordingly argue for the development of "a social science of positive community and positive institutions" (Seligman and Csikszentmihalyi 2000:12; see also Gable and Haidt 2005:110), in order to address the "extra-psychological factors that facilitate (or impede) the pursuit of the good life," including relationships and work environment (Linley et al. 2006: 7). Thus positive psychology emphasizes not only work on the self, but also institutional and government sponsorship of programs that encourage work on the self (Miller 2008:592). Seligman and Csikszentmihalyi (2000:7), for instance, argue that "[m]uch of the task of prevention in this new century will be to create a science of human strength whose mission will be to understand and learn how to foster [...] positive virtues in young people." Programs such as SEAL in the UK, focused on "the social and emotional aspects of learning," draw directly on this orientation (Miller 2008:592).

This is where happiness economics enters the picture. ${ }^{6}$ As its key proponents put it, happiness economics combines economic and psychological methods in order to provide "a new evidence-based vision of how we can live better" that is based on "the new psychology of happiness" (Layard 2006:ix). Specifically, happiness economics works to complement income based measures of welfare with broader measures of well-being derived from largescale, cross-national surveys (Graham 2008). In addition to providing the grounds for non-income based determinants of happiness, the survey results are used to make recommendations regarding potential government interventions designed to create the conditions of possibility for well-being (Anielski 2007; Frey 2008; Frey and Stutzer 2002; Layard 2006). These range from welfare-state type interventions, to efforts to increase government transparency and direct democracy, to programs making the kinds of individualized therapies lauded by positive psychology, such as Cognitive Behavioral Therapy, more widely available and integrated into a range of institutions, including those serving the general population, like schools, churches and recreation facilities, as well as those targeting the marginalized - criminals, the unemployed, the mentally ill, the drug-addicted, and so on (Bok, D. 2010; Ferguson 2007; Miller 2008).

Positive psychology and happiness economics appear straightforward: they present knowledge, policy, and even the achievement of happiness as almost transparently mechanical - a matter of applying the right technique. Both approaches are highly problematic, however, insofar as they universalize the culturally specific and serve to erase the power relations they buttress (as well as their role in providing this support). Two phenomena in particular - happiness indexes and taxonomies of positive personality characteristics - place these weaknesses into relief.

\section{Happiness indexes ${ }^{7}$}

Although developed in primarily EuroAmerican contexts, the survey measures deployed by happiness economists are taken to be valid cross-culturally; likewise the indexes they produce are asserted as objective and accurate. Several of these indexes are quite well known, e.g., the Happiness in Nations Index, the Happy Planet Index, the Satisfaction with Life Index, and the UN Development Index. Drawing on a range of measures, the indexes produce rankings of countries' happiness. The Happiness in Nations Index, for instance, ranks countries on

${ }^{6}$ Although there are differences between popular psychology and happiness economics, my focus here is on what they share and on how they build on each other.

${ }^{7}$ While all happiness indexes universalize culturally specific measures, not all indexes are necessarily handmaidens to structures of power; indeed, the intention in some cases is to buttress structural change for liberatory purposes. Thus, as I discuss below, some indexes focus not only on perceptions of subjective well-being, but also on issues related to life expectancy, environmental sustainability, and democracy - any of which could provide justification for resource redistribution. 
the basis of respondents' answers to questions about subjective well-being. Others, such as the Happy Planet and Satisfaction with Life indexes combine questionnaire responses about subjective well-being with statistical data on life expectancy, ecological footprint, and other social and economic indicators. And since 2011, the UN Development Index has focused on three key measures: life expectancy, education, and income. ${ }^{8}$ Given the range of measures deployed, and the fact that different governments collect and format statistical data differently, it should come as no surprise that these indexes produce different results. At this writing, for instance, Costa Rica ranks at the top of the Happiness in Nations Index, Vanuatu is at the top of the Happy Planet Index, the Satisfaction in Life Index ranks Denmark as number one, and the UN Development Index ranks Norway at the top. There is considerable variation, then, in both international rankings and the place that individual countries occupy in different indexes. ${ }^{9}$

One of the most problematic aspects of these indexes is that they reflect an obsession with measurement (Thin 2005:4), in keeping with the "excessively quantitative methodology" of positive psychology (Fernández-Ríos and Cornes 2009:10). This is partly an artifact of positive psychology's attempt to situate itself in opposition to popular psychology, and in particular, to the popular self-help movements that its proponents feel have been generated by such sub-disciplines as humanistic psychology. In their initial overview of positive psychology, for instance, Seligman and Csikszentmihalyi (2000:7) work to establish positive psychology as an empirically based science, in contrast to approaches based on "wishful thinking, faith, self-deception fads, or hand waving." Linley et al., in the inaugural issue of The Journal of Positive Psychology, cite a number of definitions of the discipline that similarly highlight a scientific orientation - e.g., positive psychology as "the scientific study of ordinary human strengths and virtues" (Sheldon \& King, 2001:126; cited in Linley et al. 2006:5) - and they themselves define it as "the scientific study of optimal human functioning" (ibid.: 8). They also express concern about the "immense temptation for positive psychology to descend into popularist science," and argue strongly in favor of "scientific rigor" and "first class empirical work" (ibid.:11).

It is difficult, however, from an anthropological perspective, not to be skeptical about the scientific rigor and first class empiricism of questions like, "Taking it all together, how satisfied or dissatisfied are you with your life-as-a-whole these days?" - Which is a key question asked in the Happiness in Nations surveys. Of course this question can be translated literally into local languages, but what does "taking it all together" mean, in the context of, for example, reincarnation? By what standards, in other words, does one calculate one's "life-as-a-whole"? And what do "satisfied" and "dissatisfied" mean? Are these always locally relevant concepts, and, if so, what are their specific valences? And what is it that satisfaction or dissatisfaction are supposedly attached to? Oneself? One's family? One's accomplishments? One's connections with dead ancestors, spirits, or other animal species? What, indeed, counts as a person, a family, an accomplishment? And what does it mean for someone in, say, a village in Samoa, to be asked this question by someone with a clipboard or tape recorder? Are the interviewer and respondent having dinner together? Are they in the middle of what we commonly call an "interview"? What does an "interview" mean in Samoa? My point here is that we need to carefully attend to how questions about subjective well-being are asked - in what context and of whom - and how they might be interpreted. Without some kind of

8 Although not international in orientation, Canada's Index of Well-being, traditionally focused on health, democratic engagement, the environment, and time use, among other indicators, has recently added surveys focused on subjective well-being.

${ }^{9}$ Canada, for instance, ranks fifth on the UN Index, and tenth on the Satisfaction in Life Index, but doesn't even make the top 50 on the Happy Planet Index. 
understanding of these processes and contexts, it is all too likely that what is happening is a form of communicative hegemony (Briggs 1986): the imposition of a culturally specific frame of communication in other contexts. Employing pre-determined "objective" measures and often forced choice answers to set questions, the methods used to generate happiness indexes tend to gloss over how cultures conceive of, experience, and express happiness and well-being in different ways (Matthews and Izquierdo 2009:7) - if those are even relevant local constructs. Such methods may thus tell us more about the cultural systems in which they are developed than about the people or social systems being analyzed.

\section{Personality characteristics}

Positive psychology's categorization of personality characteristics is equally troubling. In Character Strengths and Virtues: A Handbook and Classification, a foundational text in positive psychology, Peterson and Seligman (2004) provide a catalogue of what they refer to as "key virtues" and "signature strengths." The method for producing these categorizations was itself glaringly ethnocentric. First, nine (EuroAmerican based) scholars "created a tentative list of human strengths" (2004:14-15). These were shared with several other scholars and checked against literatures in a number of disciplines as well as the writings of key (western) historical figures. "Statements made by the Boy Scouts of America and the Girl Guides of Canada," as well as "virtue-relevant messages in Hallmark greeting cards, bumper-stickers, Saturday Evening Post covers by Norman Rockwell, personal ads, popular song lyrics, graffiti, Tarot cards, the profiles of Pokémon characters, and the residence halls of Hogwarts" were also thrown into the mix" (15). The result was a list of six key virtues - courage, justice, wisdom, humanity, temperance, and transcendence - that were then compared with what Peterson and Seligman constructed as the great three philosophical traditions of China, India and the West (ibid.:34). It is on this basis that Peterson and Seligman claim cross-cultural relevance. It is worth wondering, however, if it is "really so surprising to find commonality where one looks for it [...] It is one thing to look at other cultures and to try to understand them on their own terms, it is quite another to develop a list and then check off similarities" (Christopher and Hickinbottom 2008: 578). The latter methodological approach is sloppy and simplistic: it glosses over differences as if they were a mere matter of semantic detail, ignoring in the process specificity and contextualization. As with questionnaires on subjective well-being, personality characteristics are here abstracted from their contexts of occurrence, including their interaction with other personality traits and with the cultural surrounds. It is as if they were free-floating objective entities, as if we could put them on like clothing, as if "the social and material context[s] in which people are born, live and die" (Fernandez-Rios and Cornes 2009:10) are irrelevant.

\section{Fa'asamoa}

To correct for this kind of ethnocentrism, a more culturally sensitive approach is required - specifically, fine-grained, nuanced ethnographic analyses of how happiness and well-being (or whatever happen to be the relevant constructs) are conceived, practiced, and experienced in specific cultural contexts. Such an approach promises to provide a counter-balance to survey methods that are insufficiently culturally grounded, or that, in presenting themselves as objective, fail to acknowledge their cultural origins. In addition, an ethnographic approach can complement large-scale cross-national projects by providing foundations for more appropriate and therefore more accurate forms of comparison. As such, it can contribute "one more essential piece to the puzzle of well-being considered worldwide" (Mathews and Izquierdo 2009:5). My argument, then, is not that we should dismiss the project of exploring issues related to happiness cross-culturally; rather, it is that we should undertake such explorations in ways that do not violate the integrity or reduce the complexity of cultural systems. A brief overview of fa' asamoa will serve to make this methodological point. In addition, fa' asamoa provides both an alternative view worth exploring in and of itself, and a set of insights into the specificity of EuroAmerican approaches. 
Fa'asamoa is an explicitly articulated model of the good life focused on collective orientations built around allegiance to a system of hierarchically organized matai (chiefs) and to one's 'aiga (extended family). At the foundation of fa'asamoa is the cultivation of a particular set of personal attributes, including generosity, respect, courage and fortitude, and service, entailing obedience and submissiveness to one's superiors in age and chiefly title (Drozdow-St. Christian 2002; Freeman 1982; Holmes and Holmes 1992; Mageo 1998; Mead 1938; Shore 1982). Most notable for my purposes is the emphasis on suppressing one's own will, or loto (variously translated as the inner self, passion, heart, feeling, thinking, intention), in favor of the will of the 'aiga (Mageo 1998). Thus the Samoan term for self, aga, refers to social conduct and persona, rather than to an essentialized interior essence. Traditional Samoan culture has accordingly been characterized as ideologically and normatively (if not always in practice) more sociocentric than egocentric (ibid.).

Samoans openly celebrate and assert fa'asamoa as the best model for being-in-the-world. The song, Le Aganu'u Samoa (Samoan Custom), for instance, claims "Samoan custom is the best of all countries/ Happiness and respect to people" (Mageo 1998: 3; 242-3, n.1). Indeed, Coming of Age in Samoa, Margaret Mead's 1928 account of adolescence in Samoa, was, in effect, a treatise on happiness written for a popular (and presumably unhappy) U.S. audience. In it, she claimed that Samoans were well adjusted and free of neuroses relative to Americans. Among the many reasons Mead provided for this state of affairs, two stand out: the lack of emphasis in Samoan culture on interiority; and the extremely narrow range of life paths on offer in Samoa, which, Mead argued, serves to reduce both conflict (among competing choices), and the need to take responsibility (for making the "right" choice). This is in stark contrast to palagi (EuroAmerican) models of happiness and well-being as dependent on freedom of choice in the service of personal fulfillment. Like EuroAmerican models, fa'asamoa depends on self-governance, but with an emphasis on vigilance and self-discipline in the interests of the 'aiga rather than the self. This, it is claimed, will produce "happiness and respect" for all.

This relatively collectivist versus individualist orientation indexes general differences between Samoan and EuroAmerican constructs of the person. In dominant EuroAmerican culture, the person has a more or less stable essence that endures across space and time. We may act differently around bosses versus lovers versus friends versus family, and we may change as we age, but there is, underneath it all, a continuity. This reflects, of course, a focus on interiority. Samoan persons, in contrast, are not characterized by this kind of essence or continuity. Instead, the person is fundamentally oriented externally, and expressions of the self are multifaceted and profoundly contextdependent. Nor do Samoans set up a EuroAmerican oppositional relationship between the individual and the collective, in which contributing to the collective is constructed as either compromising of the self or undertaken in instrumental service to the self (such as doing volunteer work in order to feel good). Loto may take a back seat to the 'aiga, but there does not seem to be the same kind of pull and tug between the two in Samoa. ${ }^{10}$ Nor is the Samoan construction of the person unique. On the contrary, some would argue that the contemporary EuroAmerican approach to the individual is what is unique (Geertz 1975; Keene 1978; Author 2002; Levy 1973; Lutz 1988; Shore 1982).

Given these contrasts, fa' asamoa provides a useful point of departure for situating EuroAmerican models. Most obviously, as already discussed, fa'asamoa places into relief EuroAmerican individualism. Less obviously, fa'asamoa highlights the EuroAmerican assumption that thoughts matter. Popular psychology, and, in particular,

${ }^{10}$ As Keene (1978:61-2) explains, "there is little stress [in Samoa] on individual moral autonomy. There is no lonely struggle against temptation as the thrust of the system is to minimize tempting situations." 
much of the self-help movement, is foundationally based on this (taken-for-granted) idea. To draw from the extreme end of popular psychology, the "law of attraction" articulated in the film and book "The Secret" and its sequel, "The Power," argues, as one New Yorker commentator has put it, that "thoughts have physical power" (Sanneh 2010:75). A similar, albeit not as extreme, ethos permeates positive psychology, as even a superficial glance at Seligman's Authentic Happiness (2002) and Learned Optimism (2006) indicates: positive and negative thoughts produce positive and negative outcomes, respectively (Ehrenreich 2009, 2010). Despite the efforts of positive psychology to distinguish itself from popular psychology, then, the two agree that optimism "makes happy outcomes more likely" (Ehrenreich 2010:3). Positive psychology accordingly claims that "people can be recrafted into goal achievers able to control their emotions and harness all their positive energies in the service of their goals" (Miller 2008:595). This kind of materiality of thought, which I think is crucial to EuroAmerican constructions of happiness, is not at all the focus in Samoan culture, where primacy of place is given to action, as opposed to thought, to such an extent that in traditional Samoan jurisprudence, intention is not of primary concern (Keene 1978).

The story of fa'asamoa is even more complicated, however, insofar as fa'asamoa (like most indigenous, non-EuroAmerican cultural formations) has not existed without challenge. As Mead described in 1928, missionization presented an alternative to fa'asamoa, altering the social and personal landscape, including the gender regime, by encouraging a focus on the inner self and on forms of status external to the matai system (Mead 1928; see also Mageo 1998; Macpherson \& Macpherson 2009). American military personnel stationed in Samoa during WWII also brought with them individualized notions of romance, further emphasizing interiority (Mageo 1998; Shankman 2009). Colonialism, immigration, and the accelerated travel of ideologies of consumerism and individual rights accompanying contemporary forms of globalization have further disrupted traditional Samoan approaches to social organization (Macpherson \& Macpherson 2009). Nevertheless, Samoans continue to assert and practice fa'asamoa even as they engage in palagi ways (Holmes and Holmes 1992; Macpherson \& Macpherson 2009). The Samoan government itself has worked to address these tensions by creating a hybrid of fa'asamoa, on the one hand, and a Westminster system, representing distinctively palagi approaches to person and society, on the other. Thus the Samoan Constitution (Government of Samoa 1960) established a unicameral legislative assembly comprised of 49 members, of which 47 have to be matai, and has Articles $(100,102)$ focused on "Samoan custom and usage" with regard to both title succession and land use. At the same time, Part II of the Constitution enshrines a series of "fundamental [individual] rights" including the rights to life, personal liberty, a fair trial, religious choice, and so on.

Any detailed analysis of Samoan cultural formations, then, would have to take into account these kinds of negotiations between fa'asamoa and fa'apalagi, in order to avoid romanticized constructions of intact indigenous systems. Similar kinds of negotiations no doubt occur in other non-EuroAmerican societies that have been missionized and/or colonized. In addition, EuroAmerican societies themselves are also no doubt marked by such negotiations: thus the emphasis in some Canadian and U.S. circles on volunteerism (although often undertaken in service to the self), the existence of a range of First Nations/Native American cultures and religious organizations that exhibit strong strands of anti-individualism, and the proliferation of intentional communities. ${ }^{11}$ Mixed systems, and the conversations among various models, thus warrant close attention. Nevertheless, this brief overview of fa'asamoa indicates that contemporary cultures of happiness are not only historically specific, as I argued in the

${ }^{11}$ There are well over 500 intentional communities (with at least an equal number in formation) in Canada and the United States alone (www.ic.org), although some are very small. Intentional communities tend to fall into one of four categories: ecological, cooperative/socialist, religious/spiritual, and disability. 
previous section, but also culturally specific. If fa'asamoa represents a unique cultural formation, why should we assume that the models presented by positive psychology and happiness economics are not similarly culturally unique?

\section{Governance}

Having established the historical and cultural specificity of the EuroAmerican approach to happiness, I now turn to its relationship to forms of neoliberal governance. Studies of neoliberalism - as a cultural, economic and political system that valorizes the free market, privatization, and individualism - have tended to focus on the obviously negative impacts of its policies: structural adjustment, welfare reform, deregulation leading to economic crises, etc. However, neoliberalism also claims, in utopic fashion, that if markets are freed from state intervention and if individuals are accordingly liberated to be their naturally autonomous and entrepreneurial selves, the result will be a healthy economy producing a properly functioning society comprised of happy, self-fulfilled individuals (Bourdieu 1998; McDonald and O'Callaghan 2008; Peck 2013; Rose 1996). Clearly, the work of governance that gets done at the margins - the policing and regulation of welfare recipients, the homeless, the "others" to the market, and the inmates of carceral society, for instance - is essential to this project; but so is the work that gets done in the so-called center, in the taken-for-granted, mundane everyday lives of proper middle and upper-class subjects. The latter is every bit as time-consuming and costly as that targeting society's rejects, and is also every bit as crucial to the operations of power and governance. We need, in other words, to investigate more closely the mundane, yet foundational, practices of what has become a distinctively neoliberal culture of happiness.

There are two important points to note about the relationship between happiness and neoliberalism. First, it just so happens that the type of person most valorized by neoliberalism is the type of person most valorized by positive psychology. Positive psychology and neoliberalism both emphasize - and attempt to render normative - a particular personality type: the self-examining, self-governing, autonomous, positive, entrepreneurial self (Miller 2008, Ehrenreich 2009, 2010; McDonald and O'Callaghan 2008). Take, for example, the following statement: "No longer do dominant theories view the individual as a passive vessel responding to stimuli; rather, individuals are now seen as decision makers, with choices, preferences, and the possibility of becoming masterful [and] efficacious." Although written by the founders of positive psychology (Seligman and Csikszentmihalyi 2000:8), this statement mirrors claims made by pundits of the "active society" (see Author 2013; Walters 1997). In the latter case, we have a buttress for the gutting of social programs - really, the disassemblage of the social - in the name of selfsufficiency and so-called empowerment. Dolan and White (2008:77), for instance, although not calling specifically for the elimination of the welfare state, advocate the use of measures of subjective well being to determine whom to target with programs designed to increase resilience and "positive affective experiences." This kind of targeting can in turn serve to justify the elimination of welfare programs, as Ferguson's (2007) discussion of British efforts to slash the Incapacity Benefit while expanding psychological programs designed to teach people how to look after themselves indicates. ${ }^{12}$ In the former case, we have an approach that has become near hegemonic in mainstream orientations to happiness, similarly placing pressure on people to look after themselves. It is "as if positive psychology were a...manifestation of the technical and instrumental rationality" of neoliberalism (Fernández-Ríos and Cornes 2009:10).

${ }^{12}$ See also Goode (2002) and Korteweg (2006), for discussion of this process in the context of U.S. welfare reform. 
Second, except when it is intervening in peoples' lives in the most illiberal ways, neoliberalism is a form of government-at-a-distance: the goal is to encourage self-governance in place of state government. In this framework, responsibility for happiness, just like responsibility for poverty and risk more generally, is devolved to the level of the individual. This is the case even with happiness economics, despite its support of government programs, since it approaches the latter as fundamentally about making available particular programs that allow individuals to pursue happiness. Thus in the contemporary culture of happiness, we are all enjoined to work on ourselves in order to become happier and more fulfilled, and there is a plethora of technologies of self devoted to this enterprise, all designed to enable us to craft ourselves into the kinds of persons most valued in our society. In this radically individualized neoliberal terrain, if we are unhappy, we have only ourselves to blame.

Significantly, in being held (and holding ourselves) responsible for our own happiness, our analysis of our lives is channeled in particular directions. The approaches to the self advocated by positive psychology and happiness economics are thus usefully conceptualized as disciplinary techniques - and, significantly, ones members of the middle- and upper- classes undertake voluntarily. As forms of governance, these techniques orient us away from political economy and structures of inequality and towards a particular form of destructured, non-or post-social personhood. "Rather than assuming that happiness is simply found in "happy persons,"” then, we could think more carefully about "how claims to happiness make certain forms of personhood valuable" (Ahmed 2010:11). In working to transform ourselves into such valuable persons, our focus becomes fixed on individual mental attitudes. We can become so engrossed in monitoring ourselves for evidence of negativity and working on ourselves to cultivate positivity that we fail to monitor what is happening outside of ourselves, and remove ourselves from collective engagement - thereby contributing to the decollectivization that Bourdieu (1998) claimed is one of the biggest dangers of neoliberalism.

The happiness we are enjoined to seek, moreover, is located ahead of us, just over a continually advancing horizon. Thus it should come as no surprise that future-mindedness is one of the personality traits positive psychologists want us to cultivate (Seligman and Csikszentmihalyi 2000:5). In order to ready ourselves for something both ineffable and endlessly deferred but profoundly desired, we are, as I've already noted, directed to make use of the various technologies of self available to us - a directive, not trivially, that is hugely beneficial to the booming markets in therapy, pharmaceuticals and various other forms of self-help. Hard as we might work now to set the stage for then, then remains remote, always out of reach. However, gratification is not completely put on hold, as we can participate, endlessly, in markets geared towards the happy future - or towards the alleviation of the anxiety that the requirement for happiness generates in the present.

The emergence of happiness as an obsession also supports the market for and popularity of science. Happiness "science" - even, in this case, a measurement obsessed (Thin 2005; Fernández-Ríos and Cornes 2009) enterprise based on sloppy methods and an unthinking, ethnocentric universalizing of culturally and historically specific constructions - has thus increasingly become the arbiter and architect of our future happiness: it buttresses and encourages an obsession with predictability and future-oriented control.

In this confluence of academic disciplines and the disciplinary institutions of governments and markets, happiness as a goal, as a project to be worked on, as something we each have the responsibility to achieve, and as a specifically individual project having to do with personal desire and motivation, has taken on a Gramscian valence of common sense, less ideological and subject to contestation, and more taken-for-granted, natural, and received (Comaroff and Comaroff 1991; Gramsci 1971; Williams 1977). In both positive psychology and happiness economics, any future social utopia is predicated on self-work oriented towards future individual utopias (if we can apply that term to something that is not, in fact, collective). If, as Foucault claimed, power operates best via its own erasure, here is a perfect example: the diversion of attention from structure to the self, and the self-assertion of 
power vis-à-vis one's own self in ways that contribute to that erasure of structure.

\section{Conclusion}

Given that the culture of happiness marks a diffuse, large-scale development, in this discussion I have followed only a few select threads of its emergence and orientations in my attempt to denaturalize what we have come to take for granted about what happiness is, how to achieve it, and its importance in our lives. I have not, for instance, discussed neuroscience or particular religious traditions, but have instead focused on what I see as two of the most powerful influences on how we currently think about well-being: positive psychology and happiness economics.

A key artifact of the un-reflexive universalization of historically and culturally unique perspectives is the buttressing of particular power relations that erode the social. Instead, we need to carefully situate our work on happiness and well-being - in academic, policy, and personal arenas - in historical and cultural context. There is nothing in our current conceptualizations or practices that is transparently self-evident, there is nothing to take for granted, and there is certainly nothing that can be easily universalized across time and space. It is only by reflecting on the historical and cultural contexts of our categories of analysis, investigation, and action that we can gain insight into how our work relates to forms of governance and the interests that they serve - which may or may not be in the best interests of either our own selves or the societies in which we live.

If we want to seriously explore issues related to happiness and well-being, we need to follow the positive psychologists and happiness economists in calling for first-class empirical work. Such work, however, does not impose culturally and historically specific categories of analysis, measuring instruments and agendas onto cultures with different orientations, but rather, attends to nuance in order to earnestly, accurately, and with openness explore the myriad ways in which various human groups have arrived at particular approaches to thinking about and acting on what is most important in life. We may even learn something positive from this.

\section{Acknowledgements}

I would like to thank Katie Aubrecht, David Reggio, Claudia Malacrida, John Mayer, and the anonymous reviewers for Health, Culture and Society for their contributions to my thinking and writing. Research for this article was supported by a University of Lethbridge University Scholar Research Chair.

\section{References}

Ahmed, S. 2010 The promise of happiness. Durham and London: Duke University Press.

Anielski, M. 2007The economics of happiness: Building genuine wealth. Gabriola Island, BC: New Society Publications

Bok, D. 2010 The politics of happiness: What government can learn from the new research on well-being. Princeton: Princeton University Press. 
Bok, S. 2010 Exploring happiness: From Aristotle to brain science. New Haven: Yale University Press.

Bourdieu, P. 1998 Acts of resistance: Against the tyranny of the market. NY: The New Press.

Briggs, C. 1986 Learning how to ask: A sociolinguistic appraisal of the role of the interview in social science research. Cambridge: Cambridge University Press.

Christopher, J.C., \& Hickinbottom, S. 2008 Positive psychology, ethnocentrism, and the disguised ideology of individualism. Theory \& psychology, 18(5), 563-589.

Comaroff, J., \& Comaroff, J.L. 1991 Of revelation and revolution: Christianity, colonialism, and consciousness in South Africa, vol. 1. Chicago: University of Chicago Press.

Csikszentmihalyi, M. 1990 Flow: The psychology of optimal experience. New York: Harper Collins.

Csikszentmihalyi, M. 1997 Creativity: Flow and the psychology of discovery and invention. New York: Harper Collins.

Dolan, P., Peasgood, T., \& White, M. 2006 Review of research on the influences on personal well-being and application to policy making. Retrieved 12/11/12, www.sustainabledevelopment.gov.uk/publications/pdf/WellbingProject2.pdf

Dolan, Paul, \& White, M. 2007 How can measures of subjective well-being be used to inform public policy? Perspectives on psychological science 2(1), 71-85.

Douglas, Mary, \& Ney, S. 1998 Missing persons: A critique of personhood in the social sciences. Berkeley: University of California Press and the Russell Sage Foundation.

Drozdow-St. Christian, Douglass 2002 Elusive Fragments: Making Power, Propriety and Health in Samoa. Durham: Carolina Academic Press.

Ehrenreich, B. 2009 Bright sided: How the relentless promotion of positive thinking has undermined America. NY: Henry Holt.

Ehrenreich, B. 2011 The delusion of positive thinking. Therapy today. Retrieved 29/09/12, www.therapytoday.net

Fernández-Ríos, \& Cornes, J.M. 2009 A critical review of the history and current status of positive psychology. Annuary of clinical and health psychology, 5,7-13.

Ferguson, I. 2007 Neoliberalism, happiness and well-being. International socialism 117, 1-15. Retrieved 6/12/12, www.isj.org.uk

Freeman, Derek 1982 Margaret Mead and Samoa: The Making and Unmaking of an Anthropological Myth. Harmondsworth: Penguin.

Frey, B.S. 2008 Happiness: A revolution in economics. Cambridge: MIT Press.

Frey, B.S., \& Stutzer, A. 2002 Happiness and economics. Princeton: Princeton University Press.

Gable, S.L., \& Haidt, J. 2005 What (and why) is positive psychology? Review of general psychology 9(2),103-110.

Geertz, C. 1975 On the nature of anthropological understanding. American scientist, 63, 47-53.

Gilbert, D. 2006 Stumbling on happiness. Toronto: Vintage. 
Goode, J. 2002 From New Deal to bad deal: Racial and political implications of U.S. welfare reform. In Kingfisher, C., ed., Western welfare in decline: Globalization and women's poverty. Philadelphia: University of Pennsylvania Press.

Government of Samoa 1960 Constitution of the independent state of Samoa 1960. Apia: Government of Samoa.

Graham, C. 2008 The economics of happiness. In Durlauf, S. \& Blume, L., eds., The new Palgrave dictionary of economics, $2^{\text {nd }}$ ed. New York: Palgrave Macmillan.

Gramsci, A. 1971 Selections from the prison notebooks. New York: International Publishers.

Gunnell, B. 2004 The Happiness Industry. New statesman 133(4704),10-12.

Holmes, L.D., \& Holmes, E.R. 1992 Samoan village: then and now, $2^{\text {nd }}$ ed. Fort Worth: Harcourt Brace Jovanovich College Publishers.

Johnston, B.R., Colson, E., Falk, D., St. John, G., Bodley, J.H., McCay, B.J., Wali, A., Nordstrom, C. \& Slyomovics, S. 2012 On happiness. American anthropologist 114(1), 6-18.

Kingwell, M. 1998 Better living: In pursuit of happiness from Plato to Prozac. Toronto: Penguin.

Korteweg, A.C. 2006 The politics of subject formation: Welfare-reliant women's response to welfare reform in the United States and the Netherlands. In Marston, G., \& McDonald, C., Analysing social policy: A governmental approach. Camberley: Edward Elgar.

Layard, R. 2006 Happiness: Lessons from a new science. Harmondsworth: Penguin.

Levy, R. 1973 Tahitians. Chicago: University of Chicago Press.

Linley, P.A., Joseph, S., Harrington, S., \& Wood, A.M. 2006 Positive psychology: Past, present, and (possible) future. Journal of positive psychology 1(1), 3016.

Lutz, C.A. 1988 Unnatural emotions: Everyday sentiments on a Micronesian atoll and their challenge to western theory. Chicago: University of Chicago Press.

Macpherson, C., \& Macpherson, L. 2009 The warm winds of change: Globalisation in contemporary Samoa. Auckland: Auckland University Press.

Mageo, J.M. 1998 Theorizing self in Samoa: Emotions, genders, and sexualities. Ann Arbor: University of Michigan Press.

Mathews, G., \& Izquierdo, C. 2009 Anthropology, happiness, and well-being. In pursuits of happiness: Well-being in anthropological perspective. New York \& Oxford: Berghahn Books.

McMahon, D.M. 2006 Happiness: A history. New York: Grove Press.

2010 What does the ideal of happiness mean? Social research 77(2), 469-490.

Miller, A. 2008 A critique of positive psychology - or 'the new science of happiness.' Journal of philosophy of education 42(3-4), 591-608.

McDonald, M. \& O’Callaghan, J. 2008 Positive psychology: A Foucauldian critique. The humanistic psychologist $36,127-142$.

Peck, J. 2013 Explaining (with) neoliberalism. Territory, politics, governance. DOI:10.1080/21622671.2013.785365 
Peterson, C., \& Seligman, M.E.P. 2004 Character strengths and virtues: A handbook and classification. Oxford: Oxford University Press.

Rose, N. 1996 Inventing our selves: Psychology, power, and personhood. Cambridge: Cambridge University Press. Sanneh, Kelefa 2010 Power lines: What's behind Rhonda Byrne's spiritual empire. The New Yorker, September 13.

Shankman, P. 2009 The trashing of Margaret Mead: Anatomy of an anthropological controversy. Madison: University of Wisconsin Press.

Schumaker, J.F. 2007 In search of happiness: Understanding an endangered state of mind. Westport, CT: Praeger.

Seligman, M. 2002 Authentic happiness: Using the new positive psychology to realize your potential for lasting fulfillment. New York: The Free Press.

2006 Learned optimism: How to change your mind and your life. New York: Vintage.

Seligman, M. \& Csikszentmihalyi, M. 2000 Positive psychology: An introduction. American psychologist 55, 1-14.

Stiglitz, J.E., Sen, A., \& Fitoussi, J.P. 2009 Report by the commission on the measurement of economic performance and social progress (commissioned by President Nicolas Sarkozy). Retrieved 1012/12, http://www.stiglitz-sen-fitoussi.fr/documents/rapport anglais.pdf

Taylor, C. 1989 Sources of the self: The making of modern identity. Cambridge, MA: Harvard University Press.

Thin, N. 2005 Happiness and the sad topics of anthropology. University of Bath: Well-being in developing countries working paper No. 10.

Thin, N. 2009 Why anthropology can ill afford to ignore well-being. In Mathews, G., \& Izquierdo, C., eds., Pursuits of happiness: Well-being in anthropological perspective. New York \& Oxford: Berghahn Books.

Thin, N. 2012 Social happiness: Theory into policy and practice. Bristol: The Policy Press.

UN News Centre Happiness should have a greater role in development policy. 19 July 2011. Retrieved 1/4/12, www.un.org

Walters, W. 1997 The active society: new directions for social policy. Policy and politics 25(3), 221-234.

Weiner, E. 2008 The geography of bliss. New York: Twelve Books.

Williams, R. 1977 Marxism and literature. Oxford: Oxford University Press. 